\title{
An integrated heat efficiency model for superheated steam injection in heavy oil reservoirs
}

\author{
Congge He*, Anzhu Xu, Zifei Fan, Lun Zhao, Angang Zhang, Fachao Shan, and Jun He \\ Research Institute of Petroleum Exploration \& Development, PetroChina, 20 Xueyuan Road, Haidian, Beijing 100083, China
}

Received: 28 September 2018 / Accepted: 24 October 2018

\begin{abstract}
Accurate calculation of heat efficiency in the process of superheated steam injection is important for the efficient development of heavy oil reservoirs. In this paper, an integrated analytical model for wellbore heat efficiency, reservoir heat efficiency and total heat efficiency was proposed based on energy conservation principle. Comparisons have been made between the new model results, measured data and Computer Modelling Group (CMG) results for a specific heavy oil reservoir developed by superheated steam injection, and similarity is observed, which verifies the correctness of the new model. After the new model is validated, the effect of injection rate and reservoir thickness on wellbore heat efficiency and reservoir heat efficiency are analyzed. The results show that the wellbore heat efficiency increases with injection time. The larger the injection rate is, the higher the wellbore heat efficiency. However, the reservoir heat efficiency decreases with injection time and the injection rate has little impact on it. The reservoir thickness has no effect on wellbore heat efficiency, but the reservoir heat efficiency and total heat efficiency increase with the reservoir thickness rising.
\end{abstract}

\section{Nomenclature}

A Temperature gradient of the hot fluid zone, ${ }^{\circ} \mathrm{C} / \mathrm{m}$

$A_{\mathrm{h}} \quad$ Pseudo area of hot-fluid-zone, $\mathrm{m}^{2}{ }^{\circ} \mathrm{C}$

$A_{\mathrm{s} 1} \quad$ The area of saturated steam-zone top, $\mathrm{m}^{2}$

$A_{\mathrm{s} 2} \quad$ The area of saturated steam-zone bottom, $\mathrm{m}^{2}$

$A_{\mathrm{sh} 1}$ The area of superheated steam-zone top, $\mathrm{m}^{2}$

$A_{\mathrm{sh} 2}$ The area of superheated steam-zone bottom, $\mathrm{m}^{2}$

$C_{\mathrm{p}} \quad$ The heat capacity of superheated steam, $\mathrm{J} /\left(\mathrm{kg}{ }^{\circ} \mathrm{C}\right)$

$f(t)$ The transient heat-conduction time function

$f_{\mathrm{w}} \quad$ The friction factor of pipe flow

$g \quad$ Gravitational acceleration, $\mathrm{m}^{2} / \mathrm{s}$

$H$ Thickness of pay zone, $\mathrm{m}$

$h_{\mathrm{c}} \quad$ The convective heat transfer coefficient, $\mathrm{W} /\left(\mathrm{m}^{2}{ }^{\circ} \mathrm{C}\right)$

$h_{\mathrm{D}} \quad$ The dimensionless specific enthalpy of superheated steam, dimensionless

$h_{\mathrm{r}} \quad$ The radiative heat transfer coefficient, $\mathrm{W} /\left(\mathrm{m}^{2}{ }^{\circ} \mathrm{C}\right)$

$h_{\mathrm{s}} \quad$ The specific enthalpy of saturated steam, $\mathrm{J} / \mathrm{kg}$

$h_{\mathrm{sh}} \quad$ The specific enthalpy of superheated steam, $\mathrm{J} / \mathrm{kg}$

$h_{\mathrm{sh}} \quad$ The specific enthalpy of superheated steam, $\mathrm{J} / \mathrm{kg}$

$h_{\mathrm{w}} \quad$ The specific enthalpy of hot water, $\mathrm{J} / \mathrm{kg}$

$i_{\mathrm{s}} \quad$ Injection rate of superheated steam, $\mathrm{kg} / \mathrm{s}$

$l \quad$ The well depth, $m$

$L_{\mathrm{v}} \quad$ Latent heat of vaporization of steam, $\mathrm{J} / \mathrm{kg}$
$M \quad$ Steam override coefficient, dimensionless

$M_{\mathrm{R}} \quad$ Heat capacity of reservoir, $\mathrm{J} /\left(\mathrm{m}^{3}{ }^{\circ} \mathrm{C}\right)$

$P \quad$ The pressure of superheated steam, $\mathrm{MPa}$

$Q_{\mathrm{c}} \quad$ The heat flow from superheated steam to the surrounding formation, $\mathrm{J}$

$Q_{\mathrm{hi}} \quad$ The heat injection rate of hot fluid zone, $\mathrm{J} / \mathrm{s}$

$Q_{\mathrm{ib}} \quad$ The energy of superheated steam at the bottomhole, $\mathrm{J} / \mathrm{s}$

$Q_{\text {ih }} \quad$ The energy of superheated steam at the wellhead, $\mathrm{J} / \mathrm{s}$

$Q_{\mathrm{oh}} \quad$ The heat growth of hot fluid zone, J

$Q_{\text {os }} \quad$ The heat growth of steam zone, J

$Q_{\text {osh }}$ The heat growth of superheated steam zone, J

$Q_{\text {shi }}$ The heat injection rate of superheated steam zone, $\mathrm{J} / \mathrm{s}$

$Q_{\mathrm{si}} \quad$ The heat injection rate of steam zone, $\mathrm{J} / \mathrm{s}$

$R \quad$ Radial distance into reservoir, $\mathrm{m}$

$r_{\mathrm{bh}} \quad$ The radius of hot-fluid-zone bottom, $\mathrm{m}$

$r_{\mathrm{ci}} \quad$ The inside radius of casing, $\mathrm{m}$

$r_{\text {co }} \quad$ The outside radius of casing, $\mathrm{m}$

$r_{\mathrm{h}} \quad$ The outside radius of cementing, $\mathrm{m}$

$r_{\text {ins }}$ The outside radius of insulation, $m$

$r_{\mathrm{ti}} \quad$ The inside radius of tubing, $\mathrm{m}$

$r_{\text {to }} \quad$ The outside radius of tubing, $m$

$t \quad$ Injection time, $\mathrm{s}$

$T_{0} \quad$ The formation temperature, ${ }^{\circ} \mathrm{C}$

* Corresponding author: hecongge1988@163.com 
$t_{\mathrm{D}} \quad$ Dimensionless time, dimensionless

$T_{\mathrm{r}} \quad$ Initial reservoir temperature, ${ }^{\circ} \mathrm{C}$

$T_{\mathrm{s}} \quad$ The saturated steam temperature, ${ }^{\circ} \mathrm{C}$

$T_{\mathrm{sh}}$ The superheated steam temperature, ${ }^{\circ} \mathrm{C}$

$\frac{T_{\text {sh }}}{T}$ The average temperature of superheated zone, ${ }^{\circ} \mathrm{C}$

$U_{\text {to }}$ The overall heat transfer coefficient, $\mathrm{W} /\left(\mathrm{m}^{2}{ }^{\circ} \mathrm{C}\right)$

$V \quad$ The velocity of superheated steam, $\mathrm{m} / \mathrm{s}$

$V_{\mathrm{s}} \quad$ The volume of the steam zone, $\mathrm{m}^{3}$

$V_{\text {sh }}$ The volume of the superheated steam zone, $\mathrm{m}^{3}$

\section{Greek letters}

\begin{tabular}{|c|c|}
\hline$\alpha_{\mathrm{s}}$ & $\begin{array}{l}\text { Thermal diffusivity of the cap and } \\
\text { base rock, } \mathrm{m}^{2} / \mathrm{d}\end{array}$ \\
\hline$\beta$ & Factor, dimensionless \\
\hline$\gamma$ & The specific volume of superheated steam, $\mathrm{m}^{3} / \mathrm{kg}$ \\
\hline$\delta$ & $\begin{array}{l}\text { The instant at which the boundary becomes } \\
\text { exposed to the hot fluid, d }\end{array}$ \\
\hline$\eta_{\mathrm{r}}$ & The reservoir heat efficiency, dimensionless \\
\hline$\eta_{\mathrm{w}}$ & The wellbore heat efficiency, dimensionless \\
\hline$\eta_{\mathrm{t}}$ & The total heat efficiency, dimensionless \\
\hline$\theta$ & The well angle from horizontal, ${ }^{\circ}$ \\
\hline$\lambda_{\text {cas }}$ & $\begin{array}{l}\text { The thermal conductivity of the casing, } \\
\mathrm{W} /\left(\mathrm{m}^{\circ} \mathrm{C}\right)\end{array}$ \\
\hline$\lambda_{\text {cem }}$ & $\begin{array}{l}\text { The thermal conductivity of the cement, } \\
\mathrm{W} /\left(\mathrm{m}^{\circ} \mathrm{C}\right)\end{array}$ \\
\hline$\lambda_{\text {ins }}$ & $\begin{array}{l}\text { The thermal conductivity of the insulation, } \\
\mathrm{W} /\left(\mathrm{m}^{\circ} \mathrm{C}\right)\end{array}$ \\
\hline$\lambda_{\mathrm{s}}$ & $\begin{array}{l}\text { Thermal conduction coefficient of formation, } \\
\mathrm{W} /\left(\mathrm{m}^{\circ} \mathrm{C}\right)\end{array}$ \\
\hline$\lambda_{\text {tub }}$ & The thermal conductivity of the tube, $\mathrm{W} /\left(\mathrm{m}{ }^{\circ} \mathrm{C}\right)$ \\
\hline$\rho$ & The density of superheated steam, $\mathrm{kg} / \mathrm{m}^{3}$ \\
\hline
\end{tabular}

\section{Introduction}

Nowadays, the thermal recovery methods, such as cyclic steam stimulation (Gina and Hugo, 2011; Tewari et al., 2011; Wu and Kry, 1993), steam drive (Du et al. 2012; Shie and Todd, 1980; Wu et al., 2015), steam assisted gravity drainage (Miura and Wang, 2010; Wei et al., 2014) are still the most extensively adopted enhanced oil recovery process in heavy oil reservoirs. In those thermal recovery methods, high-temperature steam is injected into the pay zone, and therefore the viscosity of heavy oil decreases and its flow ability is improved (Liu et al., 2008a; Yu and Zhang, 2016; Yu, 2001) During the process of steam injection, not all heat carried by the steam can be used to heat the pay zone, because part of heat will loss to surrounding formation during the steam flowing in the wellbore and part of heat will loss to the cap and base rock as steam enters the pay zone (Liu, 1997; Roger, 1991). Therefore, accurate calculation of heat efficiency in the process of steam injection is important for high efficient development of heavy oil reservoirs.
As steam flows in the wellbore, the temperature and pressure of steam will change with well depth. In early research, a mass of investigations have been conducted on the steam temperature prediction by analytical models (Gu et al., 2014, 2015; Holst and Flock, 1966; Ni and Cheng, 2005; Ramey, 1962; Satter, 1965). As superheated steam is obtained by continually heating the saturated steam at constant pressure, the temperature and pressure of superheated steam do not accord with one-to-one relationship as saturated steam (Bulter, 1991; Chen, 1996). Therefore, those previous models cannot be used to predict the temperature and pressure of superheated steam. The authors and their team considered the feature of superheated steam and established analytical models to predict the temperature and pressure of superheated steam in both vertical wellbore and horizontal wellbore (Fan et al., 2016; Xu et al., 2009), which were adopted to calculate the wellbore heat efficiency in this paper.

Marx and Langenheim (1959) established a classical analytical model to calculate the heat area of steam injection based on energy conservation principle. Even though Marx-Langenheim model did not consider the temperature decrease in the hot fluid zone and also ignored the steam overlay effect, it was the pioneering work in this research field. Van Lookeren (1977) built an analytical model to describe the steam overlay effect. Based on Van Lookeren steam overlay theory, Lai et al. (2014) and He et al. (2017a) improved the steam injection model. Liu et al. (2008b) and He et al. (2018b) built models for heat area along horizontal wellbore due to the fact that the heat mechanism of horizontal wellbore and vertical wellbore (Fig. 1) is different. Baker (1969) did an experiment to study the temperature distribution of pay zone in the process of steam injection, and the result shows that the steam zone temperature keeps constant and the hot fluid zone temperature gradually decreases from steam temperature to the initial reservoir temperature. Based on it, $\mathrm{Li}$ and Yang (2003) and He et al. (2015) improved the heat area calculation model by considering the non-isothermal distribution of temperature in pay zone. It should be pointed out that these models derived on the basis of steam injection, they do not apply to superheated steam injection. This is due to the fact that the distribution of temperature in pay zone in the process of superheated steam injection and conventional saturated steam injection is totally different (Zhou et al., 2010). He et al. (2017b) established an analytical model to calculate the heat radius by considering the distribution of temperature in pay zone in the process of superheated steam injection. However, this model didn't consider the steam overlay effect.

Compared with conventional saturated steam, superheated has higher temperature and carried much more heat, besides, superheated steam can change the microscopic pore structure of rock to improve the permeability of superheated steam heat area (Xu et al., 2013). Therefore, superheated steam injection is very appropriate for development of heavy oil reservoirs and this thermal recovery method has been applied in oilfield in China and Kazakhstan (Guan, 2011; Li et al., 2008, 2012).The authors and their team have done a series of studies on the application of 


\section{Superheated steam injection}

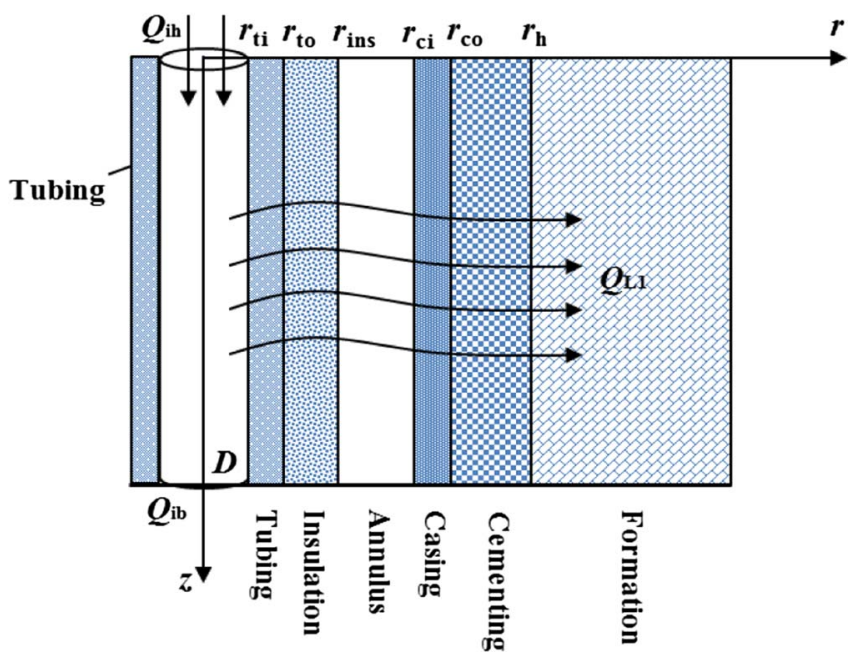

Fig. 1. Schematic of vertical wellbore.

superheated steam injection (He et al., 2017b, 2018a; Wu et al., 2010; Xu et al., 2009). Based on previous studies, the authors begin to focus on the prediction of heat efficiency of superheated steam injection. In this paper, an integrated analytical model for wellbore heat efficiency, reservoir heat efficiency and total heat efficiency was proposed based on energy conservation principle. Comparisons have been made between the new model results, measured data and Computer Modelling Group (CMG) results for a specific heavy oil reservoir developed by superheated steam injection. Finally, the effect of injection rate and reservoir thickness on wellbore heat efficiency and reservoir heat efficiency are analyzed based on the proposed model.

\section{Mathematical model}

\subsection{Wellbore heat efficiency model}

The basic assumptions of wellbore heat efficiency model include

1. The mass flow rate and the temperature of superheated steam at the wellhead do not change with injection time.

2. Heat transfer from the inside of tubing to the outside of cementing is steady state, but heat transfer from the outside of cementing to the formation is nonsteady state.

As superheated steam flows in the wellbore, the pressure changes with the well depth. The pressure gradient of superheated steam in the wellbore can be given as

$$
\frac{\mathrm{d} p}{\mathrm{~d} l}=\frac{\rho g \sin \theta-f_{\mathrm{w}} \frac{\rho v^{2}}{4 r_{\mathrm{ti}}}}{1-\frac{\rho v^{2}}{p}}
$$

where $p$ is the pressure of superheated steam; $\rho$ is the density of superheated steam; $g$ is the gravitational acceleration; $\theta$ is the well angle from horizontal; $l$ is the depth of well; $f_{\mathrm{w}}$ is the friction factor of pipe flow; $v$ is the velocity of superheated steam; $r_{\mathrm{ti}}$ is the inside radius of tubing.

Based on the law of energy conservation, we have

$$
\frac{\mathrm{d} Q_{\mathrm{c}}}{\mathrm{d} l}=-i_{\mathrm{s}} \frac{\mathrm{d} h_{\mathrm{sh}}}{\mathrm{d} l}-i_{\mathrm{s}} \frac{\mathrm{d}}{\mathrm{d} l}\left(\frac{v^{2}}{2}\right)+i_{\mathrm{s}} g \sin \theta,
$$

where $\mathrm{d} Q_{\mathrm{c}} / \mathrm{d} l$ is the rate of heat flow from superheated steam to the surrounding formation; $i_{\mathrm{S}}$ is the superheated steam injection rate; $h_{\mathrm{sh}}$ is the specific enthalpy of superheated steam.

Based on the basic thermodynamic principles, the change of specific enthalpy of superheated steam can be expressed as ( $\mathrm{Gu}$ et al., 2015)

$$
\frac{\mathrm{d} h_{\mathrm{sh}}}{\mathrm{d} l}=C_{\mathrm{p}} \frac{\mathrm{d} T_{\mathrm{sh}}}{\mathrm{d} l}+\left[\gamma-T_{\mathrm{sh}}\left(\frac{\partial \gamma}{\partial T_{\mathrm{sh}}}\right)\right] \frac{\mathrm{d} p}{\mathrm{~d} l},
$$

where $T_{\mathrm{sh}}$ is the superheated steam temperature; $\gamma$ is the specific volume of superheated steam; $C_{\mathrm{p}}$ is the heat capacity of superheated steam.

Combining equations (2) and (3), the temperature gradient of superheated steam can be written as

$$
\begin{aligned}
\frac{\mathrm{d} T_{\mathrm{sh}}}{\mathrm{d} l}= & -\frac{1}{C_{\mathrm{p}}}\left\{\frac{1}{i_{\mathrm{s}}} \frac{\mathrm{d} Q_{\mathrm{c}}}{\mathrm{d} l}+\left[\gamma-T_{\mathrm{sh}}\left(\frac{\partial \gamma}{\partial T_{\mathrm{sh}}}\right)\right] \frac{\mathrm{d} p}{\mathrm{~d} l}\right. \\
& \left.+\frac{\mathrm{d}}{\mathrm{d} l}\left(\frac{v^{2}}{2}\right)+g \sin \theta\right\} .
\end{aligned}
$$

In equation (4), the rate of heat flow from superheated steam to the surrounding formation, $\mathrm{d} Q_{\mathrm{c}} / \mathrm{d} l$, can be expressed as (Fan et al., 2016)

$$
\frac{\mathrm{d} Q_{\mathrm{c}}}{\mathrm{d} l}=2 \pi r_{\mathrm{to}} U_{\mathrm{to}} \lambda_{\mathrm{s}} \frac{T_{\mathrm{sh}}-T_{0}}{r_{\mathrm{to}} U_{\mathrm{to}} f(t)+\lambda_{\mathrm{s}}},
$$

where $r_{\text {to }}$ is the outside radius of tubing; $T_{0}$ is the formation temperature; $\lambda_{\mathrm{s}}$ is the thermal conduction coefficient of formation; $f(t)$ is the transient heat-conduction time function; $t$ is injection time; $U_{\text {to }}$ is the overall heat transfer coefficient between the fluid and the cement/formation interface, which can be expressed as

$$
\begin{aligned}
U_{\text {to }}= & {\left[\frac{r_{\text {to }}}{\lambda_{\text {tub }}} \ln \frac{r_{\text {to }}}{r_{\text {ti }}}+\frac{r_{\text {to }}}{\lambda_{\text {ins }}} \ln \frac{r_{\text {ins }}}{r_{\text {to }}}+\frac{r_{\text {to }}}{\left(h_{\mathrm{c}}+h_{\mathrm{r}}\right) r_{\text {ins }}}\right.} \\
& \left.+\frac{r_{\text {to }}}{\lambda_{\text {cas }}} \ln \frac{r_{\text {co }}}{r_{\text {ci }}}+\frac{r_{\text {to }}}{\lambda_{\text {cem }}} \ln \frac{r_{\mathrm{h}}}{r_{\text {co }}}\right]^{-1},
\end{aligned}
$$

where $r_{\mathrm{ti}}, r_{\mathrm{ins}}, r_{\mathrm{ci}}, r_{\mathrm{co}}$ and $r_{\mathrm{h}}$ are the inside radius of tubing, the outside radius of insulation, the inside radius of casing, the outside radius of casing and the outside radius of cementing, respectively; $\lambda_{\text {tub }}, \lambda_{\text {ins }}, \lambda_{\text {cas }}$ and $\lambda_{\text {cem }}$ are the thermal conductivity of the tube, insulation, casing and the cement, respectively; $h_{\mathrm{c}}$ and $h_{\mathrm{r}}$ are the convective heat transfer coefficient and the radiative heat transfer coefficient, respectively.

As superheated steam is obtained by continually heating the saturated steam at constant pressure, the temperature 
and pressure of superheated steam do not accord with one-to-one relationship as saturated steam. Combining equations (1)-(6), the temperature and pressure of superheated steam along the wellbore can be obtained by iterative method. The specific enthalpy of superheated steam is function of its temperature and pressure, which can be calculated by the empirical equation as follows (He et al., 2017b)

$$
\begin{aligned}
h_{\mathrm{sh}}= & 2242.8+2.857 T_{\mathrm{sh}}-\frac{11413.9}{T_{\mathrm{sh}}}-29.03 p \\
& +\frac{283.9}{p}-\frac{0.8917 T_{\mathrm{sh}}}{p},
\end{aligned}
$$

where $h_{\mathrm{sh}}$ is the specific enthalpy of superheated steam.

The wellbore heat efficiency, $\eta_{\mathrm{w}}$, is defined as the ratio of the energy of superheated steam at the bottomhole to the energy of superheated steam at the wellhead, that is

$$
\eta_{\mathrm{w}}=\frac{Q_{\mathrm{ib}}}{Q_{\mathrm{ih}}} \times 100 \%=\frac{h_{\mathrm{sh}, z=1}}{h_{\mathrm{sh}, z=0}} \times 100 \%,
$$

where $\eta_{\mathrm{w}}$ is the wellbore heat efficiency; $Q_{\mathrm{ih}}$ is the energy of superheated steam at the wellhead; $Q_{\mathrm{ib}}$ is the energy of superheated steam at the bottomhole; $h_{\mathrm{sh}, z=0}$ and $h_{\mathrm{sh}, z=l}$ are the specific enthalpy of superheated steam at the wellhead and bottomhole, respectively.

\subsection{Reservoir heat efficiency model}

The basic assumptions of reservoir heat efficiency model are as follows.

1. As superheated steam is injected into the pay zone, there is no liquid in the wellbore and three zones are formed based on the temperature distribution of pay zone as Figure 2 shows.

2. Due to the fact that the superheated degree (the temperature difference between superheated steam and saturated steam) usually is not very high, the temperature of superheated zone is simplified to the arithmetic mean value of the superheated steam temperature and the saturated steam temperature. The temperature of steam zone equals to the saturated steam temperature. The temperature of hot fluid zone is simplified to linear decrease from saturated steam temperature to initial reservoir temperature. Besides, the temperature gradient of hot fluid zone at different reservoir vertical positions is constant.

3. The steam overlay effect of superheated zone and saturated zone is assumed to be identical as litter difference between superheated steam density and saturated steam density (as shown in Fig. 3).

\subsubsection{Heat growth of superheated zone}

According to energy conservation principle of superheated zone, we can get (Carslaw and Jaeger, 1986; He et al., 2017b)

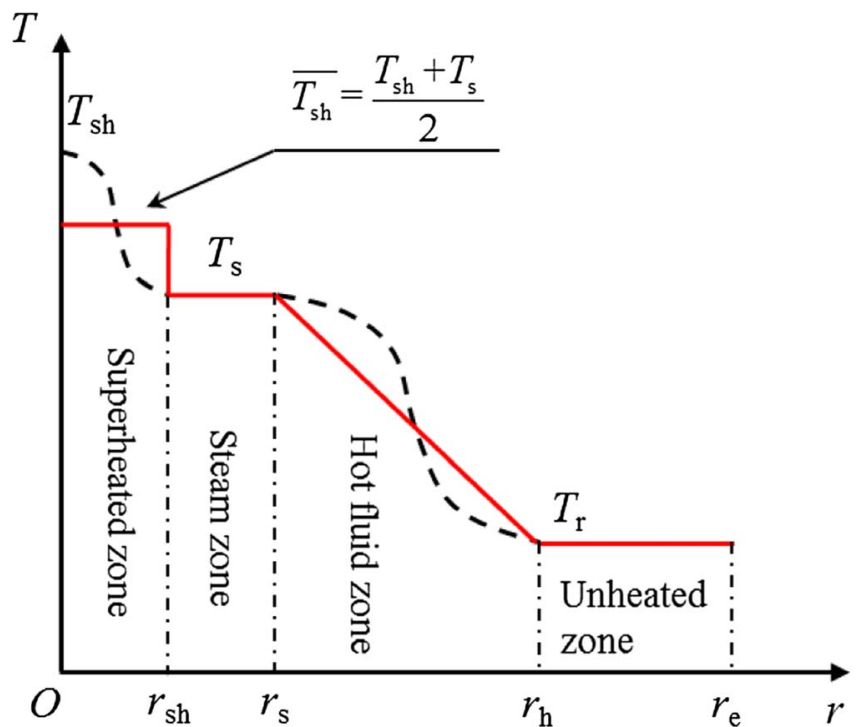

Fig. 2. Temperature distribution of pay zone (the dotted line is true temperature distribution and the red solid line is the approximate distribution applied in this new model).

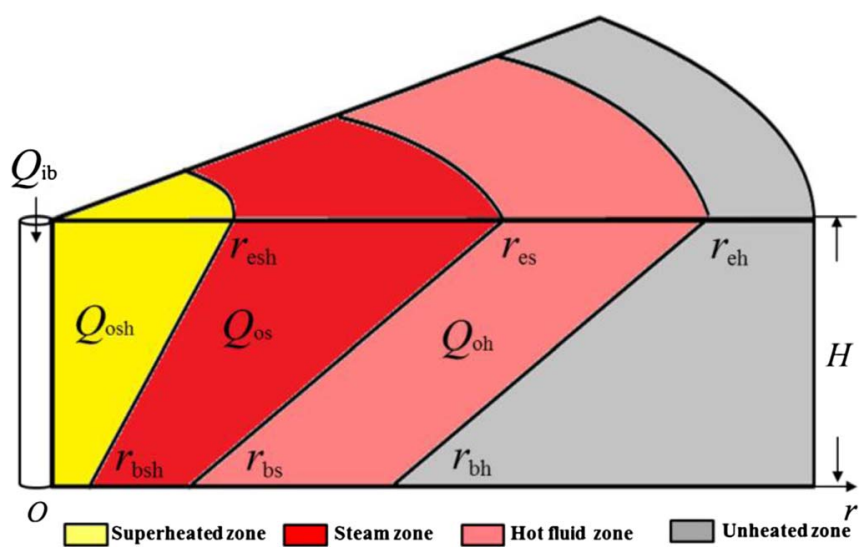

Fig. 3. Schematic of superheated zone, steam zone and hot fluid zone in the process of superheated steam injection.

$$
\begin{aligned}
Q_{\text {shi }}= & \int_{0}^{t} \frac{\lambda_{\mathrm{s}}\left(\overline{T_{\mathrm{sh}}}-T_{\mathrm{r}}\right)}{\sqrt{\pi \alpha_{\mathrm{s}}(t-\delta)}} \frac{\mathrm{d}\left(A_{\mathrm{sh} 1}+A_{\mathrm{sh} 2}\right)}{\mathrm{d} \delta} \mathrm{d} \delta \\
& +M_{\mathrm{R}}\left(\overline{T_{\mathrm{sh}}}-T_{\mathrm{r}}\right) \frac{\mathrm{d} V_{\mathrm{sh}}}{\mathrm{d} t},
\end{aligned}
$$

where $Q_{\text {shi }}$ is the heat injection rate of superheated steam zone, and $Q_{\mathrm{shi}}=i_{\mathrm{s}}\left(h_{\mathrm{sh}}-h_{\mathrm{s}}\right) ; i_{\mathrm{s}}$ is the superheated steam injection rate; $h_{\mathrm{sh}}$ and $h_{\mathrm{s}}$ are the specific enthalpy of superheated steam and saturated steam, respectively; $M_{\mathrm{R}}$ is the heat capacity of reservoir; $\lambda_{\mathrm{s}}$ is the thermal conduction coefficient of formation; $\overline{T_{\mathrm{sh}}}$ is the average temperature of superheated zone, and $\frac{\mathrm{sh}}{T_{\mathrm{sh}}}=\left(T_{\mathrm{sh}}+T_{\mathrm{s}}\right) / 2, T_{\mathrm{sh}}$ is the superheated steam temperature; $T_{\mathrm{s}}$ is the saturated steam temperature; $A_{\mathrm{sh} 1}$ and $A_{\mathrm{sh} 2}$ are the area of superheated steam-zone top and bottom, respectively; $V_{\text {sh }}$ is 
superheated steam zone volume; $t$ is the injection time; $\delta$ is the instant at which the cold boundary becomes exposed to the hot fluid; $\alpha_{\mathrm{s}}$ is thermal diffusivity of the cap and base rock.

Based on Van Lookeren steam overlay theory (He et al., 2017a; Van Lookeren, 1977), the areas of superheated steam-zone top and bottom satisfy $\mathrm{d} A_{\mathrm{sh} 1}=m^{2} \mathrm{~d} A_{\mathrm{sh} 2}$, in which $m$ is steam overlay coefficient. Meanwhile, the superheated steam zone is assumed to have the shape of the frustum of a cone, the superheated steam zone volume satisfies $\quad \mathrm{d} V_{\mathrm{sh}}=H\left(m^{2}+m+1\right) \quad \mathrm{d} A_{\mathrm{sh} 2} / 3$. Substituting those into equation (9), it obtains

$$
\begin{aligned}
Q_{\text {shi }}= & \frac{3\left(m^{2}+1\right)}{H\left(m^{2}+m+1\right)} \int_{0}^{t} \frac{\lambda_{\mathrm{s}}\left(\overline{T_{\mathrm{sh}}}-T_{\mathrm{r}}\right)}{\sqrt{\pi \alpha_{\mathrm{s}}(t-\delta)}} \frac{\mathrm{d} V_{\mathrm{sh}}}{\mathrm{d} \delta} \mathrm{d} \delta \\
& +M_{\mathrm{R}}\left(\overline{T_{\mathrm{sh}}}-T_{\mathrm{r}}\right) \frac{\mathrm{d} V_{\mathrm{sh}}}{\mathrm{d} t} .
\end{aligned}
$$

After Laplace transformation and inverse transformation in equation (10), the superheated steam zone volume can be written as

$$
V_{\mathrm{sh}}=\frac{Q_{\mathrm{shi}} M_{\mathrm{R}} H^{2} \alpha_{\mathrm{s}}}{4 \beta \lambda_{\mathrm{s}}^{2}\left(\overline{T_{\mathrm{sh}}}-T_{\mathrm{r}}\right)}\left[\mathrm{e}^{\beta t_{\mathrm{D}}} \operatorname{erfc}\left(\sqrt{\beta t_{\mathrm{D}}}\right)+2 \sqrt{\frac{\beta t_{\mathrm{D}}}{\pi}}-1\right],
$$

where $\beta=\frac{9\left(m^{2}+1\right)^{2}}{4\left(m^{2}+m+1\right)^{2}}, t_{\mathrm{D}}=\frac{4 \lambda_{\mathrm{s}}{ }^{2}}{M_{\mathrm{R}}^{2} H^{2} \alpha_{\mathrm{s}}} t$.

Therefore, the heat growth of superheated steam zone is

$$
\begin{aligned}
Q_{\mathrm{osh}} & =M_{\mathrm{R}}\left(\overline{T_{\mathrm{sh}}}-T_{\mathrm{r}}\right) V_{\mathrm{sh}} \\
& =\frac{Q_{\mathrm{shi}} M_{\mathrm{R}}^{2} H^{2} \alpha_{\mathrm{s}}}{4 \beta \lambda_{\mathrm{s}}{ }^{2}}\left[\mathrm{e}^{\beta t_{\mathrm{D}}} \operatorname{erfc}\left(\sqrt{\beta t_{\mathrm{D}}}\right)+2 \sqrt{\frac{\beta t_{\mathrm{D}}}{\pi}}-1\right],
\end{aligned}
$$

where $Q_{\mathrm{osh}}$ is the heat growth of superheated steam zone.

\subsubsection{Heat growth of steam zone}

Similar to superheated zone, a heat balance of steam zone can be written as

$$
\begin{aligned}
Q_{\mathrm{si}}= & \int_{0}^{t} \frac{\lambda_{\mathrm{s}}\left(T_{\mathrm{s}}-T_{\mathrm{r}}\right)}{\sqrt{\pi \alpha_{\mathrm{s}}(t-\delta)}} \frac{\mathrm{d}\left(A_{\mathrm{s} 1}+A_{\mathrm{s} 2}\right)}{\mathrm{d} \delta} \mathrm{d} \delta \\
& +M_{\mathrm{R}}\left(T_{\mathrm{s}}-T_{\mathrm{r}}\right) \frac{\mathrm{d} V_{\mathrm{s}}}{\mathrm{d} t},
\end{aligned}
$$

where $Q_{\mathrm{si}}$ is the heat injection rate of steam zone, and $Q_{\mathrm{si}}=i_{\mathrm{s}} L_{\mathrm{v}}, L_{\mathrm{v}}$ is the latent heat of saturated steam; $T_{\mathrm{s}}$ is the saturated steam temperature; $A_{\mathrm{s} 1}$ and $A_{\mathrm{s} 2}$ are the area of steam-zone top and bottom, respectively.

As the steam overlay effect of superheated zone and saturated zone is assumed to be identical, therefore, $\mathrm{d} A_{\mathrm{s} 1}=m^{2} \mathrm{~d} A_{\mathrm{s} 2}, \mathrm{~d} V_{\mathrm{s}}=H\left(m^{2}+m+1\right) \mathrm{d} A_{\mathrm{s} 2} / 3$. Combining those into equation (13) and using Laplace transformation and inverse transformation, we can obtain the steam zone volume as follows

$$
V_{\mathrm{s}}=\frac{Q_{\mathrm{si}} M_{\mathrm{R}} H^{2} \alpha_{\mathrm{s}}}{4 \beta \lambda_{\mathrm{s}}^{2}\left(T_{\mathrm{s}}-T_{\mathrm{r}}\right)}\left[\mathrm{e}^{\beta t_{\mathrm{D}}} \operatorname{erfc}\left(\sqrt{\beta t_{\mathrm{D}}}\right)+2 \sqrt{\frac{\beta t_{\mathrm{D}}}{\pi}}-1\right] .
$$

Therefore, the heat growth of steam zone is

$$
\begin{aligned}
Q_{\mathrm{os}} & =M_{\mathrm{R}}\left(T_{\mathrm{s}}-T_{\mathrm{r}}\right) V_{\mathrm{s}} \\
& =\frac{Q_{\mathrm{si}} M_{\mathrm{R}}^{2} H^{2} \alpha_{\mathrm{s}}}{4 \beta \lambda_{\mathrm{s}}{ }^{2}}\left[\mathrm{e}^{\beta t_{\mathrm{D}}} \operatorname{erfc}\left(\sqrt{\beta t_{\mathrm{D}}}\right)+2 \sqrt{\frac{\beta t_{\mathrm{D}}}{\pi}}-1\right],
\end{aligned}
$$

where $Q_{\mathrm{os}}$ is the heat growth of steam zone.

\subsubsection{Heat growth of hot fluid zone}

In the hot fluid zone, the temperature is assumed to linear decrease from saturated steam temperature to initial reservoir temperature. Therefore, a heat balance of hot fluid zone satisfies (He et al., 2017a)

$$
\begin{aligned}
Q_{\mathrm{hi}} & =\int_{0}^{t} \frac{2 \sqrt{\pi} \lambda_{\mathrm{s}}\left(2 r+m r_{\mathrm{bs}}-r_{\mathrm{bs}}\right)\left[a\left(r-r_{\mathrm{bs}}\right)+T_{\mathrm{s}}-T_{\mathrm{r}}\right]}{\sqrt{\alpha_{\mathrm{s}}(t-\delta)}} \frac{\mathrm{d} r}{\mathrm{~d} \delta} \mathrm{d} \delta \\
& +M_{\mathrm{R}} H \pi\left[a\left(r-r_{\mathrm{bs}}\right)+T_{\mathrm{s}}-T_{\mathrm{r}}\right]\left(2 r+m r_{\mathrm{bs}}-r_{\mathrm{bs}}\right) \frac{\mathrm{d} r}{\mathrm{~d} t}, \quad(16)
\end{aligned}
$$

where $Q_{\mathrm{hi}}$ is the heat injection rate of hot fluid zone, and $Q_{\mathrm{hi}}=i_{\mathrm{s}} h_{\mathrm{w}}, h_{\mathrm{w}}$ is the specific enthalpy of hot water; $r_{\mathrm{bh}}$ is the radius of hot-fluid-zone bottom; $r$ is the radial distance into reservoir; $a$ is the temperature gradient of the hot fluid zone in radius.

Let $\quad \mathrm{d} A_{\mathrm{h}}=\pi\left(2 r+m r_{\mathrm{bs}}-r_{\mathrm{bs}}\right)\left[a\left(r-r_{\mathrm{bs}}\right)+T_{\mathrm{s}}-T_{\mathrm{r}}\right] \mathrm{d} r$, and equation (16) can be rewritten as

$$
Q_{\mathrm{hi}}=\int_{0}^{t} \frac{2 \lambda_{\mathrm{s}}}{\sqrt{\pi \alpha_{\mathrm{s}}(t-\delta)}} \frac{\mathrm{d} A_{\mathrm{h}}}{\mathrm{d} \delta} \mathrm{d} \delta+M_{\mathrm{R}} H \frac{\mathrm{d} A_{\mathrm{h}}}{\mathrm{dt}},
$$

where $A_{\mathrm{h}}$ is the pseudo area of hot-fluid-zone.

After Laplace transformation and inverse transformation in equation (17), the heat growth of hot fluid zone can be written as

$$
\begin{aligned}
Q_{\mathrm{oh}} & =M_{\mathrm{R}} H A_{\mathrm{h}} \\
& =\frac{Q_{\mathrm{hi}} M_{\mathrm{R}}^{2} H^{2} \alpha_{\mathrm{s}}}{4 \lambda_{\mathrm{s}}^{2}}\left[\mathrm{e}^{t_{\mathrm{D}}} \operatorname{erfc}\left(\sqrt{t_{\mathrm{D}}}\right)+2 \sqrt{\frac{t_{\mathrm{D}}}{\pi}}-1\right] .
\end{aligned}
$$

\subsubsection{Reservoir heat efficiency}

The reservoir heat efficiency, $\eta_{\mathrm{r}}$, defined as the ratio of the heat retained in the pay zone to the total heat injected at the well bottom, is

$$
\eta_{\mathrm{r}}=\frac{Q_{\mathrm{osh}}+Q_{\mathrm{os}}+Q_{\mathrm{oh}}}{\left(Q_{\mathrm{shi}}+Q_{\mathrm{si}}+Q_{\mathrm{hi}}\right) t} \times 100 \% .
$$

Substituting equations (12), (15) and (18) into equation (19), the reservoir heat efficiency can be written as

$$
\eta_{\mathrm{r}}=\frac{1}{\left(1+h_{\mathrm{D}}\right) t_{\mathrm{D}}}\left\{\begin{array}{c}
\frac{h_{\mathrm{D}}}{\beta}\left[\mathrm{e}^{\beta t_{\mathrm{D}}} \operatorname{erfc}\left(\sqrt{\beta t_{\mathrm{D}}}\right)+2 \sqrt{\frac{\beta t_{\mathrm{D}}}{\pi}}-1\right] \\
+\left[\mathrm{e}^{t_{\mathrm{D}}} \operatorname{erfc}\left(\sqrt{t_{\mathrm{D}}}\right)+2 \sqrt{\frac{t_{\mathrm{D}}}{\pi}}-1\right]
\end{array}\right\} \times 100 \%,
$$


Table 1. Parameters related to wellbore structures, physical properties of reservoir and injected superheated steam.

\begin{tabular}{|c|c|c|c|}
\hline Parameter & Value & Parameter & Value \\
\hline Depth of well/m & 284 & $\begin{array}{l}\text { The thermal conductivity of } \\
\text { formation } /\left(\mathrm{W}\left(\mathrm{m}^{\circ} \mathrm{C}\right)^{-1}\right)\end{array}$ & 1.73 \\
\hline The inside radius of tubing/m & 0.038 & Reservoir temperature $/{ }^{\circ} \mathrm{C}$ & 18.8 \\
\hline The outside radius of tubing $/ \mathrm{m}$ & 0.0445 & Reservoir pressure/MPa & 2.38 \\
\hline The outside radius of insulation $/ \mathrm{m}$ & 0.0555 & Reservoir thickness $/ \mathrm{m}$ & 15 \\
\hline The inside radius of casing $/ \mathrm{m}$ & 0.0807 & $\begin{array}{l}\text { The thermal diffusivity coefficient of } \\
\text { the formation } /\left(\mathrm{m}^{2} \mathrm{~d}^{-1}\right)\end{array}$ & 0.108 \\
\hline The outside radius of casing $/ \mathrm{m}$ & 0.0889 & $\begin{array}{l}\text { The reservoir thermal } \\
\text { conductivity } /\left(\mathrm{W}\left(\mathrm{m}^{\circ} \mathrm{C}\right)^{-1}\right)\end{array}$ & 1.73 \\
\hline The outside radius of cement $/ \mathrm{m}$ & 0.01236 & $\begin{array}{l}\text { The heat capacity of } \\
\text { reservoir } /\left(\mathrm{kJ}\left(\mathrm{m}^{3}{ }^{\circ} \mathrm{C}\right)^{-1}\right)\end{array}$ & 2575 \\
\hline The thermal conductivity of tubing $/\left(\mathrm{W}\left(\mathrm{m}{ }^{\circ} \mathrm{C}\right)^{-1}\right)$ & 35 & $\begin{array}{l}\text { Thermal conductivity of } \\
\text { cement } /\left(\mathrm{W}\left(\mathrm{m}^{\circ} \mathrm{C}\right)^{-1}\right)\end{array}$ & 0.933 \\
\hline The thermal conductivity of casing $/\left(\mathrm{W}\left(\mathrm{m}{ }^{\circ} \mathrm{C}\right)^{-1}\right)$ & 35 & $\begin{array}{l}\text { Superheated steam pressure at } \\
\text { wellhead } / \mathrm{MPa}\end{array}$ & 3.8 \\
\hline The thermal conductivity of insulation $/\left(\mathrm{W}\left(\mathrm{m}^{\circ} \mathrm{C}\right)^{-1}\right)$ & 0.07 & $\begin{array}{l}\text { Superheated steam temperature at } \\
\text { wellhead } /{ }^{\circ} \mathrm{C}\end{array}$ & 3288 \\
\hline The thermal conductivity of cement $/\left(\mathrm{W}\left(\mathrm{m}^{\circ} \mathrm{C}\right)^{-1}\right)$ & 0.933 & $\begin{array}{l}\text { Superheated steam-injection } \\
\text { rate } /\left(\mathrm{t} \mathrm{h}^{-1}\right)\end{array}$ & 6 \\
\hline
\end{tabular}

where $\eta_{\mathrm{r}}$ is the reservoir heat efficiency; $h_{\mathrm{D}}$ is the dimensionless specific enthalpy of superheated steam, namely, $h_{\mathrm{D}}=\left(Q_{\mathrm{shi}}+Q_{\mathrm{si}}\right) / Q_{\mathrm{hi}}$.

\subsection{Total heat efficiency model}

The total heat efficiency, $\eta_{\mathrm{t}}$, defined as the ratio of the heat retained in the pay zone to the heat of superheated steam at the wellhead, is

$$
\eta_{\mathrm{t}}=\frac{Q_{\mathrm{osh}}+Q_{\mathrm{os}}+Q_{\mathrm{oh}}}{Q_{\mathrm{ih}} t} \times 100 \%=\eta_{\mathrm{w}} \cdot \eta_{\mathrm{r}}
$$

where $\eta_{\mathrm{t}}$ is the total heat efficiency.

\section{Results and discussion}

\subsection{Model verification}

To verify the correctness of the new model, a superheated steam injector well $\mathrm{W}-1$ in $\mathrm{K}$ oilfield is used as an example to calculate the wellbore heat efficiency and reservoir heat efficiency. The parameters related to wellbore structures, physical properties of reservoir and injected superheated steam are listed in Table 1.

Due to the fact that the wellbore heat efficiency depends on the specific enthalpy of superheated steam at the wellhead and wellbottom, exactly predicting pressure and temperature of superheated steam along the wellbore is a key point to accurately calculate wellbore heat efficiency. When the injection time is 100 days, the temperature and pressure of superheated steam along the wellbore predicted by the new model and measured results are compared in Figure 4. It can be seen that the calculated temperature and calculated pressure are consistent with mesured data, which supports the reliability of the wellbore heat efficiency model. On the basis, the calculated wellbore heat efficiency is $96.7 \%$. In other words, $3.3 \%$ of specific enthalpy of injected superheated steam at the wellhead is lost from stream to surrounding formation through tubing, casing, insulation and cement.

The result of reservoir heat efficiency predicted by the new model is compared to that of CMG (thermal reservoir simulator), He et al. model (He et al., 2017b) and M-L model (Marx and Langenheim, 1959). Figure 5 shows that the results predicted by He et al. model and M-L model are alike. This is because that both He et al. model and M-L model do not consider the steam overlay effect, even though He et al. model considered the actual situation that the pay zone temperature shows non-isothermal distribution. The result predicted by the new model is less than that of He et al. model and M-L model, but is better agreement with the CMG simulation result, which verifies the correctness of the new proposed reservoir heat efficiency model. This is because the new model considers the steam overlay effect and non-isothermal distribution of temperature in pay zone at the same time. It should be pointed out that there is difference between results predicted by CMG and the new model, even though the difference is small and satisfactory to engineering requirement. The reason for the difference is that the heated zone is simplified to the shape of frustum of a cone, while the heated zone actually has the shape of funnel. 


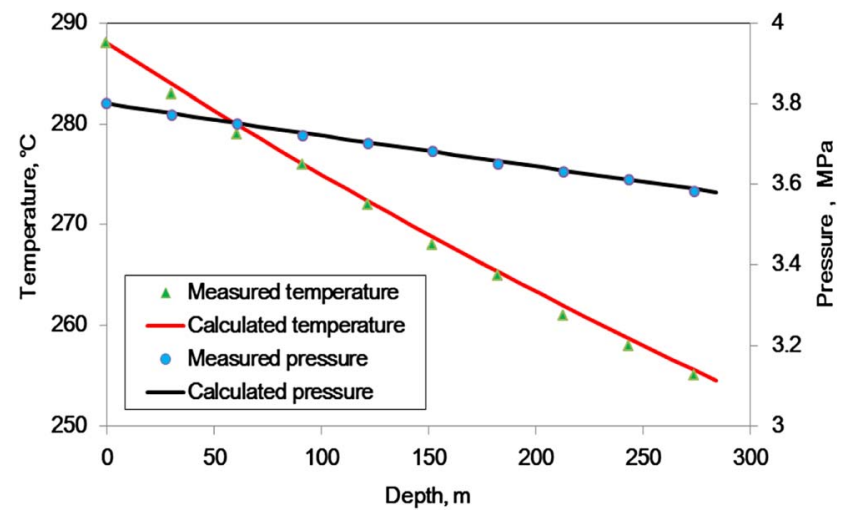

Fig. 4. Comparison of the temperature and pressure of superheated steam along the wellbore predicted by the new model and measured results.

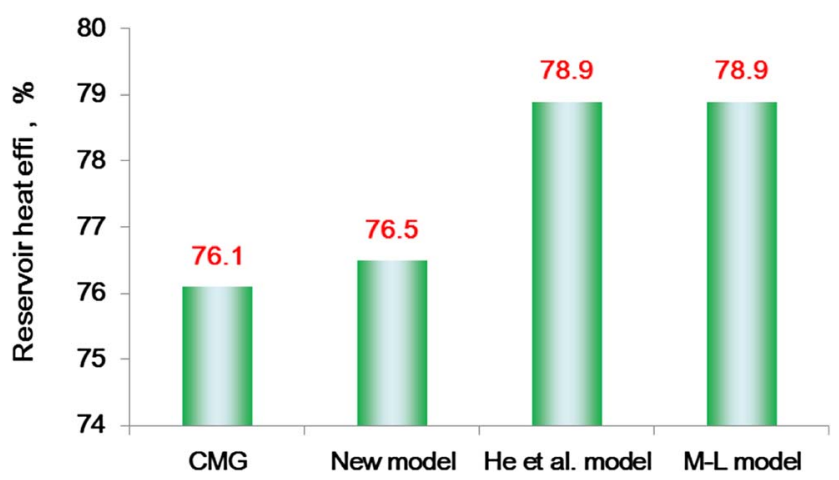

Fig. 5. Comparison of reservoir heat efficiency predicted by CMG, the new model, He et al. model and M-L model.

\subsection{Influential factors analysis}

\subsubsection{Injection rate}

Figure 6 shows the effects of injection rate on wellbore heat efficiency with different injection time. From Figure 6 , it can be seen that the wellbore heat efficiency has minimum value at the beginning of injection, and then it rapidly increases when the injection time is less 50 days. When the injection time is more than 50 days, the wellbore heat efficiency increased very slowly. This is because the heat transfers from stream to surrounding formation much more rapidly due to greater temperature difference at the beginning of injection. Moreover, Figure 6 shows that the larger the injection rate, the larger the wellbore heat efficiency. The reason is that, according equation (2), the higher injection rate, the lower heat losses of superheated steam with unit mass will be. Figure 7 shows the effects of injection rate on reservoir heat efficiency with different injection time. From Figure 7, it is clearly found that the reservoir heat efficiency decreases with injection time. For example, the reservoir heat efficiency decreases from $70.2 \%$ to $50.5 \%$ when the injection time increases from 200 days to 1000 days. This is because more and more heat is lost to cap and base rock when the injection time increases. Furthermore, Figure 7 also shows

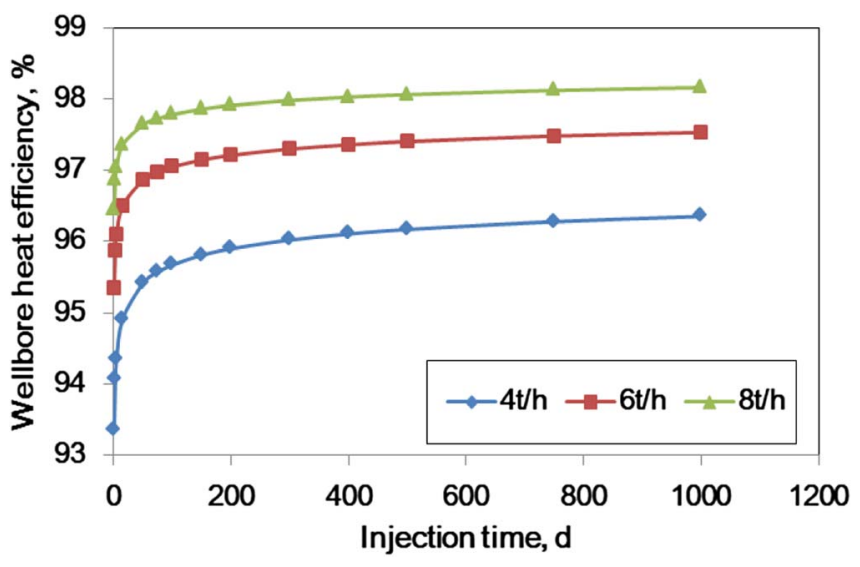

Fig. 6. Effects of injection rate on wellbore heat efficiency with different injection time.

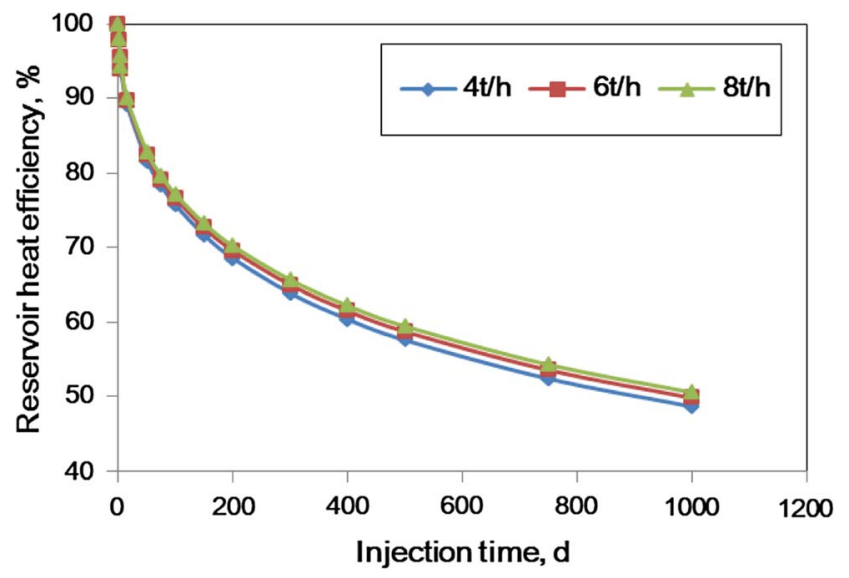

Fig. 7. Effects of injection rate on reservoir heat efficiency with different injection time.

that the injection rate has little impact on reservoir heat efficiency.

\subsubsection{Reservoir thickness}

Figure 8 shows the effects of reservoir thickness on wellbore heat efficiency, reservoir heat efficiency and total heat efficiency when injection time equals to 100 days. As shown in Figure 8, reservoir thickness has no effect on wellbore heat efficiency, but the reservoir heat efficiency and total heat efficiency increase with the increase of the reservoir thickness. For example, the reservoir heat efficiency increases from $67.7 \%$ to $80.4 \%$ when the reservoir thickness increases from $10 \mathrm{~m}$ to $20 \mathrm{~m}$. This is because the greater the reservoir thickness, the smaller the steam overlay effect, and therefore, the less heat lost to cap and base rock. It should be pointed out that when the well depth is small, the wellbore heat efficiency is very high, and the reservoir heat efficiency is much smaller than it. For example, when the well depth is $284 \mathrm{~m}$, the wellbore heat efficiency is $97 \%$, and the reservoir heat efficiency is $74 \%$ with the reservoir thickness of $15 \mathrm{~m}$. 


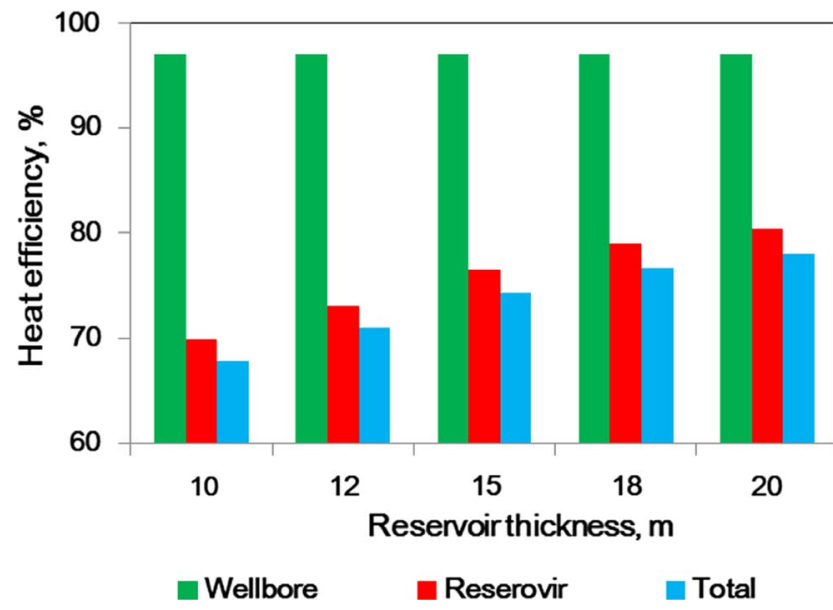

Fig. 8. Effects of reservoir thickness on wellbore heat efficiency, reservoir heat efficiency and total heat efficiency when injection time equals to 100 days.

\section{Conclusion}

The paper established an integrated analytical model to calculate wellbore heat efficiency, reservoir heat efficiency and total heat efficiency in the process of superheated steam injection in the heavy oil reservoirs. The main conclusions can be drawn as follows:

1. The new analytical model considers the change of the superheated steam temperature and pressure along the wellbore, the steam overlay effect and nonisothermal distribution of temperature in pay zone at the same time, and it was proved to be reliable in engineering calculation.

2. The wellbore heat efficiency has minimum value at the beginning of injection, and then increases rapidly, finally keeps invariability with injection time rising. Also, the larger the injection rate is, the higher the wellbore heat efficiency.

3. The reservoir heat efficiency decreases with injection time due to the fact that more and more heat is lost to cap and base rock with the increase in time.

4. The injection rate has little impact on reservoir heat efficiency, but the reservoir thickness has great impact on it. Besides, the larger the reservoir thickness, the larger the reservoir heat efficiency.

Acknowledgments. This work was supported by the Major Projects of China (2017ZX05030).

\section{References}

Baker P.E. (1969) An experimental study of heat flow in steam flooding. SPE J. 9, 89-99.

Bulter R.M. (1991) Thermal recovery of oil and bitumen, 1st edn., Prentice Hall, New Jersey.

Carslaw H.S., Jaeger J.C. (1986) Conduction of heat in solids, 2nd edn., Oxford University Press, USA, New York.
Chen Y.M. (1996) Steam injection and thermal production, 1st edn., China University of Petroleum Press, Dongying.

Du D., Hou J.G., Shi Y.L., Liu R. (2012) Calculation model of heat efficiency of steam flooding in multilayer heavy-oil reservoir based on heat interaction, J. China Univ. Petrol. 36, 2, 141-145.

Fan Z., He C., Xu A. (2016) Calculation model for on-way parameters of horizontal wellbore in the superheated steam injection, Pet. Explor. Develop. 43, 5, 733-739.

Gina V.R., Hugo B. (2011) Steam injection experiences in heavy and extra-heavy oil fields, Venezuela. Proceedings of Heavy Oil Conference and Exhibition, SPE, Kuwait.

Gu H., Cheng L., Huang S., Du B., Hu C. (2014) Prediction of thermophysical properties of saturated steam and wellbore heat losses in concentric dual-tubing steam injection wells, Energy 75, 419-429.

Gu H., Cheng L., Huang S., Li B., Fang W., Hu C. (2015) Steam injection for heavy oil recovery: modeling of wellbore heat efficiency and analysis of steam injection performance, Energy Convers. Manage. 97, 166-177.

Guan Q. (2011) Research and experiment on the shallow thin layer super heavy oil superheated steam drive development-take Louzi 27 well area as example, Petrol. Geol. Eng. 25, 2, 76-78.

He C., Mu L., Xu A., Fang S. (2015) A new model of steam soaking heating radius and productivity prediction for heavy oil reservoirs, Acta Petrol. Sin. 36, 12, 1564-1570.

He C., Mu L., Fan Z., Xu A., Zeng B., Ji Z., Han H. (2017a) An improved steam injection model with the consideration of steam override, Oil Gas Sci. Technol. - Rev. IFP Energies nouvelles 72, 6. https://doi.org/10.2516/ogst/2016026.

He C., Xu A., Fan Z., Zeng B., Ji Z. (2017b) New calculation model of the heated radius for the superheated steam injection in heavy oil reservoirs, Pet. Geol. Oilfield Develop. Daqing 36, 2 , $117-122$.

He C., Xu A., Fan Z., Zhao L., Bo B. (2018a) A new mathematical model for heat radius of cyclic superheated steam stimulation with horizontal wellbore, Math. Probl. Eng. 2018, 7601702. https://doi.org/10.1155/2018/7601702.

He C., Xu A., Fan Z., Zhao L., Cheng Y., Bo B., Luo E. (2018b) Advanced mathematical model for reservoir heat efficiency with liquid in steam-injection wellbore, Energy Sourc. A, Recovery util. Environ. Effects 41, 65-67. https://doi.org/ 10.1080/15567036.2018.1496196.

Holst P.H., Flock D.L. (1966) Wellbore behavior during saturated steam injection, J. Can Pet. Tech. 5, 184-193.

Lai L., Pan T., Hu W., Song X., Ran Q. (2014) A calculation model for thermal efficiency based on steam overlap in heavy oil steam flooding, J. Chongqing Univ. 37, 5, 90-97.

Li C., Yang B. (2003) Non-isothermal productivity predicting model of heavy crude oil exploited with huff and puff, Oil Drill. Prod. Technol. 25, 5, 89-90.

Li C., Qian G., Wu S., Yu K., Yang Y. (2008) Superheated steam quality and its application to heavy oil reservoir development by steam stimulation-an example from upsalt heavy oil reservoir in Kenjiyake field, Xinjiang Petrol. Geol. 29, 4, 495-497.

Li X., Huang Z., Fei Y. (2012) Production limit and injectorproducer parameter optimization of superheated steam soaks, Journal of Oil and Gas Technology 34, 6, 148-151.

Liu C., Cheng L., Liu Y., Pang Z. (2008a) Calculating models for heating radius of cyclic steam stimulation and formation parameters in horizontal well after soaking, Acta Petrol. Sin. 29, 1, 101-105. 
Liu H., Fan Y., Zhao D., Zhang Y. (2008b) Principles and methods of thermal oil recovery technology, 1st edn., China University of Petroleum Press, Dongying.

Liu W. (1997) Steam injection for thermal recovery of heavy oils, 1st edn., Petroleum industry press, Beijing.

Marx J.W., Langenheim R.H. (1959) Reservoir heating by hot fluid injection petroleum transactions. AIME $\mathbf{2 1 6}$, 312-315.

Miura K., Wang J. (2010) An analytical model to predict Cumulative Steam Oil Ratio (CSOR) in thermal recovery SAGD process. Proceedings of Canadian Unconventional Resources and International Petroleum Conference, Galgary, Alberta, Canada, SPE-137604-MS.

Ni X., Cheng L. (2005) Calculating models for heating area of horizontal wellbore in steam stimulation, Pet. Explor. Develop. 32, 5, 108-112.

Ramey H.J. (1962) Wellbore heat transmission, J. Petrol. Technol. 427-435.

Roger M.B. (1991) Thermal recovery of oil and bitumen, Prentice-Hall Inc, USA.

Satter A. (1965) Heat losses during flow of steam down a wellbore, J. Petrol. Tech. 17, 845-851.

Shie W.R., Todd M.D. (1980) A method for predicting oil recovery by steamflooding including the effects of distillation and gravity override, SPE J. 20, 7547.

Tewari R.D., Adballa F., Lutfi H.G., Yu K., et al. (2011), Successful cyclic steam stimulation pilot in heavy oilfield of Sudan, Proceedings of SPE Enhanced Oil Recovery Conference, Kuala Lumpur, Malaysia, SPE-144638.

Van Lookeren J. (1977) Calculation methods for linear and radial steam flow in oil reservoirs. SPE J. 23, 1-16.
Wei S., Cheng L., Huang W., Huang S. (2014) Prediction for steam chamber development and production performance in SAGD process, J. Natural Gas Sci. Eng. 19, 303-310.

Wu R.S., Kry P.R. (1993) Conformance Evolution during cyclic steam stimulation in cold lake reservoir, Proceedings of International Thermal Operations Symposium, Bakersfield, California, SPE 25795.

Wu X., Xu A., Fan H. (2010) An integrated evaluation on factors affecting the performance of superheated steam huff and puff in heavy oil reservoirs, Pet. Explor. Develop. 37, 5, 608-613.

Wu Z., Pang Z., Liu H., Wang D., Wang C.L., Wang C.J., Ye Z., Chen Y. (2015) A visible experiment on adoption of high-temperature gel for improving the development effect of steam flooding in heavy oil reservoirs, Acta Petrol. Sin. 36, 11, $1421-1426$.

Xu A., Mu L., Fan Z., Wu X., Zhao L., Bo B., Xu T. (2013) Mechanism of heavy oil recovery by cyclic superheated steam stimulation, J. Petrol. Sci. Eng. 197-207.

Xu A., Wu X., Fan Z., Li S. (2009) A comprehensive wellbore steam flow model for superheat steam injection, J. Daqing Petrol. Inst. 33, 1, 29-35.

Yu G., Zhang W. (2016) Evaluating method of the reservoir thermal efficiency considering the incomplete perforation, Petrol. Geol. Oilfield Develop. Daqing 35, 1, 80-85.

$\mathrm{Yu}$ L. (2001) Distribution of world heavy oil reservoirs and its recovery technologies and future, Spec. Oil Gas Reserv. 8, 2, 98-103.

Zhou T., Cheng L., He C., Pang Z., Zhou F. (2010) Calculation model of on-way parameters and heating radius in the superheated steam injection wellbore, Pet. Explor. Develop. 37, 1, $83-88$. 